\title{
A inesperada descoberta de Otávio lanni sobre preconceito contra descendentes de imigrantes poloneses em Curitiba*
}

Márcio de Oliveira**

Resumo: Após a pesquisa da Unesco sobre relações raciais no Brasil, Florestan Fernandes organizou e liderou uma jovem equipe para tratar do mesmo tema. A preferência recaiu então sobre os estados da Região Sul do Brasil, que não tinham feito parte da pesquisa original. Escolhidos por Florestan Fernandes, Fernando Henrique Cardoso, Roberto Jardim Moreira e Octávio lanni fizeram parte dessa equipe. Na distribuição dos estados, coube a lanni o Paraná e Santa Catarina, esse último conjuntamente com Fernando Henrique. Embora o objetivo da pesquisa fosse demonstrar a existência de preconceito nas relações raciais naqueles estados, lanni ficou surpreso em descobrir também um novo preconceito, dessa feita contra imigrantes poloneses e seus descendentes, na cidade de Curitiba, capital do Paraná. Ianni investigou inicialmente a questão e publicou alguns artigos a respeito, nos quais tentou explicar o inesperado preconceito. No intuito de dar continuidade e investigar mais a fundo o fenômeno, elaborou e publicou um projeto de pesquisa sobre o tema que, contudo, nunca veio à luz.

Palavras-chave: relações raciais, Unesco, preconceito, imigrantes poloneses, Curitiba.

\section{Introdução}

A história da sociologia brasileira foi bastante influenciada pela luta contra o racismo da Unesco, iniciada logo após a Segunda Guerra Mundial. Esse grande esforço conheceu um de seus capítulos mais fecundos quando da pesquisa sobre relações raciais, definida por representantes da Unesco em $1950^{1}$. O Brasil foi então escolhido como um terrain de recherche perfeito, principalmente porque a Unesco pretendia investigar países onde "os contatos entre os grupos raciais e étnicos" não eram conflituosos ou, pelo menos, estariam sob controle². Pesou a positiva imagem que havia sobre as relações raciais no Brasil. Uma última razão dessa escolha foi a presença do médico e professor de antropologia, Arthur Ramos (1903-1949), à frente do Departamento de Ciências Sociais da Unesco. Com efeito, Arthur tinha se tornado um crítico do racismo e sua visão sobre as relações raciais no Brasil era próxima da tese das "relações raciais harmônicas", defendida por Gilberto Freyre (1900-1987) e, mesmo reconhecendo atitudes discriminatórias na sociedade brasileira, preocupava-se fundamentalmente em como integrar os afrodescendentes à sociedade nacional (Ramos, 1948). Freyre e Ramos acreditavam que o Brasil poderia tornar-se um modelo exitoso de relações raciais harmônicas, erigindo-se assim um paradigma para qualquer outro país onde as relações raciais fossem conflituosas ${ }^{3}$.

\author{
* Este ensaio tem \\ inspiração no capítulo \\ do mesmo autor \\ publicado no livro \\ Knowledge for whom? \\ Public sociology in the \\ making, organizado \\ por Christian Fleck \\ \& Andreas Hess. Ver \\ referências. \\ Agradeço ao \\ professor Renato \\ Ortiz a sugestão e o \\ incentivo para que \\ publicasse o presente \\ ensaio, tendo em \\ vista o interesse para \\ o público brasileiro.
** Professor de sociologia na Universidade Federal do Paraná. <marciodeoliveira@ ufpr.br>. Registro aqui o agradecimento ao CNPq pelo apoio à pesquisa que deu origem ao presente ensaio.

1. A quinta sessão da Conferência Geral da Unesco publicou o documento Statement on race (1950). Para maiores detalhes, ver Maurel (2007) e Maio (1999).

2. Foram também
escolhidos, na
América Central,
a Martinica e
Guadalupe.
3. Segundo o Arthur
Ramos, o Brasil
havia mostrado ao
mundo a melhor
solução científica ao

2. Foram também escolhidos, na América Centra a Martinica e 3. Segundo o Arthur Ramos, o Brasil mundo a melhor solução científica ao 
problema da mistura racial (Ramos, 1943: 179). A esse respeito, ver Freyre \& Ramos (1937), Ramos (1942; 1946) e Campos (2003).

\section{Sobre a}

importância de Wagley para as ciências sociais brasileiras, ver: <http://www.mnsu. edu/emuseum/ information/ biography/uvwxyz/ wagley_charles_ walter.html>.

5. Pierson havia feito seus estudos e obtido seu título de PhD na Universidade de Chicago (Departamento de Sociologia), em 1939. No Brasil, organizou e dirigiu o Departamento de Sociologia e Antropologia na Escola Livre de Sociologia e Política, na cidade de São Paulo. Nessa época, publicou Brancos e preto na Bahia: estudo de contato racial (1945) [1942] e Cruz das Almas (1966) [1951]. Para maiores detalhes, ver Guimarães (2004) e Maio (2013).

6. Essa pareceria resultaria no clássico Brancos e negros em São Paulo. Para maiores detalhes, ver Pereira (1996).

7. Freyre indicou seu amigo, o antropólogo René Ribeiro, para tomar parte na pesquisa. Ribeiro havia trabalhado com ele e também com Melville Herskovits, professor
A pesquisa da Unesco foi realizada nas cidades de Recife, Salvador, Rio de Janeiro e São Paulo. Inicialmente, apenas a cidade de Salvador havia sido selecionada, devido às relações acadêmicas previamente estabelecidas entre o estado da Bahia e a Universidade de Colúmbia, onde lecionava o brasilianista Charles Wagley (1913-1991) ${ }^{4}$, e também onde um importante estudo sobre afrodescendentes tinha sido realizado no início dos anos 1940 por Donald Pierson (1900-1995)5.

A cidade do Rio de Janeiro foi mais tarde incorporada à pesquisa devido ao pedido de Luiz Aguiar da Costa Pinto (1920-2002), que havia tomado parte no debate sobre relações raciais, promovido pela Unesco em dezembro de 1949. A inclusão da cidade de São Paulo foi o resultado das relações entre Alfred Métraux (1902-1963), encarregado da pesquisa pela Unesco, e Roger Bastide (1899-1974), então professor da Universidade de São Paulo (USP), que acabaria convidando Florestan para auxiliá-lo6 . Finalmente, a cidade de Recife foi incluída a pedido de Gilberto Freyre, cujo prestígio e trabalhos sobre relações raciais no Nordeste eram por demais conhecidos, embora Freyre não tomasse parte na pesquisa ${ }^{7}$

A pesquisa da Unesco foi levada a cabo por uma equipe formada por sociólogos brasileiros e estrangeiros cujo interesse pelo tema era bastante conhecido ${ }^{8}$. Apesar da reconhecida contribuição da pesquisa para o desenvolvimento das ciências sociais brasileiras, seus resultados foram ambíguos. Maio (1999) afirma que eles não corroboraram a visão inicial da Unesco sobre o Brasil, revelando, por outro lado, a forma como a pesquisa tinha sido conduzida. O próprio Métraux (1951) ficara em dúvida em relação a não existência de preconceito racial na sociedade brasileira. 0 grupo local, à exceção de Ribeiro, mostrou que o modelo das relações raciais harmônicas - tal como descrito por Freyre - havia sido superestimado e não correspondia à realidade. O processo de modernização do Brasil aparentemente não estava conduzindo a uma sociedade plural e democrática. Esse processo não incorporava as classes baixas - em especial as camadas miscigenadas e os negros - à sociedade de consumo de massa. A principal questão apontada pela pesquisa era a mudança, em relação ao tema das relações raciais no Brasil, de um "ethos nacional" para um "problema nacional".

Após a pesquisa da Unesco, Florestan Fernandes (1920-1996), sem a presença de Roger Bastide, organizou uma equipe de jovens sociólogos para uma nova pesquisa sobre relações raciais dentro de um programa sobre o processo de modernização em curso no Sul do Brasil ${ }^{9}$. Essa nova pesquisa, consequência indireta da pesquisa da Unesco, foi apoiada pelo Instituto Nacional de Estudos e Pesquisas Educacionais (Inep), pela Coordenação de Aperfeiçoamento de Pessoal de Nível Superior (Capes) e por Charles Wagley. A preferência pela Região Sul tinha motivos claros: ela havia sido deixada de lado na pesquisa da Unesco, por três razões, a saber: 1. não havia 
se desenvolvido aí a grande exportação de produtos tropicais; 2 . a escravidão tinha sido menos intensa e menos central para o desenvolvimento econômico; e 3. a coIonização imigrante havia criado padrões de relações sociais e de relações raciais diferentes daqueles que tinham prevalecido em outras regiões do país. Além dessas razões, poucos estudos haviam sido realizados sobre aquela região, que tinha como característica um rápido processo de industrialização. Assim, havia grande interesse em observar como os afrodescendentes estavam sendo incorporados àquela sociedade de consumo de massa, influenciada enfim pela chegada de grande número de imigrantes europeus não portugueses, com sua cultura até mesmo mais racialmente estratificada daquele padrão vigente em outras partes do país.

Naquele momento, quatro novas cidades foram escolhidas: as capitais dos estados do Rio Grande do Sul, Santa Catarina e Paraná (Porto Alegre, Florianópolis e Curitiba), acrescidas da cidade de Pelotas (RS). Essas cidades foram repartidas entre os membros da jovem equipe: Fernando Henrique Cardoso, Renato Jardim Moreira ${ }^{10}$ e Octávio lanni (1926-2004). Os principais projetos foram conduzidos por Fernando Henrique e Octávio Ianni. Enquanto o primeiro trabalhou nas cidades de Porto Alegre e Pelotas, o segundo ocupou-se de Curitiba. A cidade de Florianópolis foi trabalhada conjuntamente por ambos. Nas palavras de Cardoso,

O programa foi inicialmente proposto por Florestan Fernandes para ampliar o conhecimento sobre o preconceito racial no Brasil alcançado em trabalhos anteriores de sua autoria e de Roger Bastide (Cardoso, 2003: 25).

Ianni chegou a Curitiba em 1955 para analisar as relações raciais locais. Apresentou os primeiros resultados de sua pesquisa, tendo Cardoso e Moreira como coautores, na Segunda Reunião Brasileira de Antropologia, que teve lugar na cidade de Salvador, em 1957. O título do trabalho era "Estudo sociológico das relações entre negros e brancos no Brasil". Trabalharam tanto com testemunhos orais como a partir de comportamentos cotidianos, analisando o impacto do preconceito sobre o processo de integração de afrodescendentes. Para isso, partiram da hipótese da discriminação racial previamente testada na cidade de São Paulo. Concluíram que, em termos gerais, o preconceito em Curitiba era similar àquele existente em São Paulo.

Nesse momento, porém, um fato imprevisível surgiu da investigação realizada em Curitiba: um conjunto original e inesperado de resultados - atitudes discriminatórias e testemunhos orais negativos contra descendentes de poloneses - apareceram para além dos preconceitos contra afrodescendentes. Ianni publicou assim, já em 1958, na Revista Brasiliense, o artigo "O estudo da situação racial brasileira", no qual apresentou a trajetória dos estudos raciais no Brasil. Em seguida, em 1959, na IV Reunião Brasileira de Antropologia, que teve lugar em Curitiba, apresentou na Universidade de Northwestern, que havia visitado a Bahia diversas vezes na década de 1940.

8. Dentre eles, podemos citar Arthur Ramos, Charles Wagley, Martin Harris, Oracy Nogueira, Paulo Duarte, René Ribeiro, Roger Bastide e Thales de Azevedo.

9. Bastide, aparentemente, recusou-se a fazer parte dessa nova pesquisa porque não estava interessado em estudar o processo de modernização no Brasil. Além disso, ele deixou o Brasil em 1954, retornando ao país apenas em duas oportunidades, 1962 e 1973 (Peixoto, 2000).

10. Existe muito pouca informação sobre Roberto Moreira. Sabemos apenas que ele estudou ciências sociais na Universidade de São Paulo. Em seguida, desempenhou, por um curto período, a função de professor auxiliar da cadeira de sociologia I, na mesma universidade. 
11. Não sabemos precisamente em que ano esses trabalhos foram escritos. Foram pulicados apenas em 1966, no livro Raças e classes sociais. um trabalho intitulado "Do polonês ao polaco", sobre o qual retornaremos adiante. Entre o final dos anos 1950 e o início dos anos 1960, lanni redigiu dois outros pequenos trabalhos sobre poloneses. O primeiro foi "O status social do Polonês (Projeto de estudo)" e o segundo "O sistema econômico-social e problema racial em Curitiba"11. Finalmente, nos anos 1960, lanni publicou três livros, cujos títulos são: Cor e mobilidade social em Florianópolis (1960), com Fernando Henrique Cardoso, As metamorfoses do escravo (1962) e Raças e classes sociais no Brasil (1966). Desse momento até sua morte, em 2002, nunca mais retomou o tema das relações raciais, com exceção do livro Escravidão e racismo, publicado anos mais tarde, 1978, e de algumas entrevistas.

Analisemos agora, de forma não exaustiva, o conjunto desses trabalhos sobre o tema das relações raciais no Sul do Brasil. A tese central que neles se encontra versa sobre o preconceito racial e sobre os processos de discriminação existentes nessas sociedades onde a escravidão, em termos econômicos e sociais, foi menos endêmica do que aquela encontrada em outras regiões do Brasil. Contudo, mesmo aqui, afrodescendentes ocupavam posições secundárias e os processos de ascensão social e de integração eram menos efetivos entre os últimos em comparação aos descendentes de imigrantes europeus. Em perspectiva histórica, a tese sugeria que o padrão da escravidão - forte preconceito racial aliado à obstrução da mobilidade social - permanecia forte nas relações sociais cotidianas. Contudo, lanni e Cardoso afirmaram que havia na região muito mais trabalhadores qualificados entre os afrodescendentes em comparação à situação encontrada em outras cidades brasileiras. Consequentemente, a condição social dos afrodescendentes era ligeiramente diferente. As razões disso não eram claras. Contudo, desde o início do século XIX, o sistema escravocrata não havia dominado totalmente o sistema econômico vigente no Sul do Brasil. O mercado de trabalho livre conviveu com a escravidão e havia se tornado uma alternativa tanto para os europeus recém-chegados como para escravos, e isso mesmo antes da abolição. Por outro lado, muitos imigrantes, originários em especial dos territórios germânicos e eslavos (alemães, mas também poloneses), além daqueles egressos da Rússia (russos e ucranianos) que chegaram ao estado do Paraná a partir dos anos 1870, ampliaram o sistema econômico, que até então girava em torno da exportação do mate. Tudo isso, no entanto, não havia modificado fundamentalmente as representações em torno dos afrodescendentes. Ianni afirmou que os antigos escravos se tornaram (ou metamorfosearam-se, como ele colocou no título de um de seus livros) a classe baixa da sociedade e ocupavam os postos de trabalho menos remunerados. A razão disso residia na cor de sua pele (lanni, 1962).

Todas essas descobertas representavam um passo à frente na compreensão do preconceito e do racismo no Brasil. Mas a descoberta mais desconcertante de lanni 
estava alhures: tratava-se de um novo tipo de preconceito, não necessariamente ligado ao anterior. Agora, estava-se diante de um preconceito contra descendentes de imigrantes europeus, que ocorria especificamente na cidade de Curitiba. Em suas próprias palavras, Ianni declarou ter ficado "pasmo" diante dos testemunhos orais preconceituosos, contra imigrantes e descendentes de imigrantes poloneses, que ouviu durante as entrevistas realizadas.

\section{Quem eram os imigrantes poloneses que emigraram para o Paraná?}

O primeiro grupo de imigrantes poloneses chegou a Curitiba de forma espontânea em 1870. Nessa época, o território da Polônia estava dividido e ocupado pelos impérios da Rússia, da Prússia e pelo Império Austro-Húngaro. A ocupação da Polônia durou até as vésperas da Primeira Guerra Mundial, e esse período (1870-1914) foi o que mais produziu os imigrantes que aportaram nos Estados Unidos, na Argentina e no Brasil. As causas principais dessa emigração são largamente conhecidas, indo desde a fome nas regiões rurais, à baixa produção agrícola, à pobreza e ao sonho de se tornar proprietário rural no continente americano. Esse último foi especialmente importante dentre aqueles que emigraram para a América do Sul (Oliveira, 2009).

Desembarcados no Brasil, numerosos foram os imigrantes poloneses que detinham passaportes emitidos pelas autoridades prussianas. Isso fez com que fossem enviados às chamadas zonas de colonização alemã, no Vale do Itajaí (cidades de Blumenau, Itajaí e Brusque, em Santa Catarina). Os conflitos com os imigrantes alemães estão na origem da remigração espontânea do primeiro grupo que chegou a Curitiba. Contudo, além disso, o presidente da província do Paraná, Lamenha Lins (18451881) foi particularmente importante na atração de imigrantes. Durante seu mandato (de maio de 1875 a janeiro de 1878), Lins inicialmente diferenciou a imigração subsidiada da espontânea. A partir dessa diferenciação, organizou uma política de imigração que pagava as passagens de todos aqueles que chegassem aos portos de Paranaguá (Paraná) e São Francisco do Sul (Santa Catarina) até a cidade de Curitiba. Além disso, ele estimulou a fundação de novas colônias de imigrantes nos arredores da capital do estado, beneficiando-as com a infraestrutura necessária, incluindo vias de acesso. Findo o impulso inicial feito por Lins, a imigração espontânea e, assim, irregular, foi a regra até o final do período imperial. A despeito dos esforços de Lins, apenas 7.030 poloneses chegaram ao estado do Paraná entre 1870 e 1889. Apesar do aparente pequeno número de imigrantes, o impacto deve ter sido grande porque a população de Curitiba, em 1873, não ultrapassava dois mil habitantes. Contudo, o mais relevante parece ter sido a visão positiva, aí gerada, sobre a imigração como importante fator de povoamento e de aumento da produção agrícola (Oliveira, 2007). 
12. Ironicamente, as cartas censuradas tornaram-se valioso material documental de pesquisa. Ao final de muitas delas, o censor escrevia "zadiert", resumindo em seguida seu conteúdo. A título de exemplo, na carta censurada de número 40 , o remetente escreve que se o "moscovita" permitisse, ele escreveria novamente. Em sentido inverso, as cartas "negativas" chegavam a seus destinatários e assim seu conteúdo perdeu-se no tempo.

\section{Alguns} remetentes comentavam ainda a dificuldade que tinham em enviar remessas de dinheiro aos territórios russos. Após muitas reclamações, o correio brasileiro cancelou o envio dessas remessas.
Os anos que se seguiram à Proclamação da República coincidiram com o grande fluxo de imigrantes poloneses para o Brasil. Entre 1890 e 1914, 96.116 poloneses desembarcaram na cidade do Rio de Janeiro, a imensa maioria tendo sido encaminhada às províncias do Sul. O Paraná aparece em primeiro lugar, tendo recebido 35 mil poloneses, e o Rio Grande do Sul, em segundo, com 32 mil novos imigrantes. Entre 1890 e 1894, período conhecido como a "febre brasileira", diversas colônias foram fundadas nos arredores de Curitiba e em outras regiões do estado, dentre as quais Rio Claro (3.425 colonos), Eufrosina ( 1.475 colonos) e São Mateus (1.225 colonos). Entre os anos de 1900 e 1904, período do segundo grande fluxo de imigrantes, foram fundadas as seguintes colônias: Cruz Machado (cinco mil colonos), Apucarana (mil colonos) e as colônias mistas de poloneses e ucranianos de Apucarana (10 mil colonos) e Nova Galícia (1.150 colonos).

As razões do aumento no fluxo migratório nesse novo período não devem ser procuradas nas ações empreendidas pelos governos republicanos, mas à situação nos países de partida, ainda que nem sempre favoráveis à emigração. A título de exemplo, o Império da Rússia, ao contrário da Prússia, tentaria em vão dificultar a emigração. Assim, para partir, muitos poloneses tiveram de se dirigir aos portos de Hamburgo e Bremen e aí emigraram munidos de passaportes alemães, adquiridos com recursos enviados diretamente do Brasil, gerando conflitos que estão na origem de muitos preconceitos, como lanni descobriria mais tarde. Outra forma de impedir a emigração foi a censura de determinadas cartas, enviadas por imigrantes já instalados no Brasil. Ao analisar o conteúdo dessas cartas, o historiador polonês Marcin Kula (1977) afirma que os censores russos se especializaram em não permitir que aquelas cartas com apreciações positivas do novo lar, chegassem aos seus destinatários ${ }^{12}$. O conteúdo das cartas "positivas" trazia sempre informações sobre a saúde do remetente, a menção a Deus, à terra, à abundância de florestas (onde obtinham a madeira necessária à construção de suas moradias), à beleza da natureza, da vegetação, aos animais, em especial os pássaros. O clima (o inverno ameno) era sempre comentado. A sociedade brasileira em geral, e a paranaense em particular, era descrita com cores bastante suaves. Ora era questão da "harmonia das relações sociais" (incluindo mesmo as relações entre imigrantes e ex-escravos), ora ainda eram descritas a ausência de senhores, o respeito que Ihes era dirigido pelos membros das classes abastadas e o fato de não terem impostos a pagar. As cartas terminavam sempre com o endereço do remetente, em geral, o nome da colônia onde residia ${ }^{13}$. Em suma, nessas cartas "positivas", havia um reconhecimento das relações "iguais" e o país era descrito como um bom lugar para se viver.

Além das cartas, contamos ainda com testemunhos oculares desse período, cujos relatórios e as narrativas revelam a tensão que ainda existia entre favoráveis e opositores da imigração. Dentre os últimos, os relatos de Hempel (1973) e de Klobuko- 
wski (1971) são exemplares. Ambos fizeram parte da mesma expedição enviada ao Brasil e à Argentina pela Associação Comercial de Luow, para verificar em detalhe as condições de vida dos imigrantes poloneses. Seus relatórios afirmam que, em contraste com os Estados Unidos, o Brasil, em especial seus estados sulinos, não deveriam ser vistos como um país imigrantista. Os relatos colhidos por Hempel (1973) informam-nos que eram comuns as queixas sobre as condições de higiene, o cólera ou ainda que muitas crianças não resistiam às doenças infectocontagiosas. É interessante observar, porém que Hempel (1973: 97), mesmo não tendo se tornado um adepto da emigração, não procurou impedi-la, considerando que, no Paraná, a "nossa vida nacional amplia-se, alarga-se, universaliza-se". Klobukowski, um intelectual que tinha se interessado pelo tema da imigração, foi mesmo mais longe quando afirmou que estavam aí (no Paraná) reunidas as condições para a emergência de uma "sociedade neopolonesa" (Kobukowski, 1971: 15). Mas seria possível debitar do cotidiano ou das organizações sociais típica ou exclusivamente polonesas, o teor dessas análises?

Apresentamos alhures (Oliveira, 2010), um levantamento não exaustivo das formas de organização social polonesas existentes na cidade de Curitiba, na primeira década de 1900. Assim temos a Sociedade Polono-Brasileira Tadeuz Kosciusko, fundada em 1890 com o objetivo de integrar poloneses que estavam "afastados do mundo civilizado"14. Ao lado dessa, a Sociedade de Ginástica Falcão, fundada em 1898 que mal disfarçava em práticas desportivas suas atividades paramilitares em vista da reconquista da independência polonesa. Fundado em 1901, o Círculo da Mocidade Polonesa teve como principal objetivo a autoinstrução. Dentre os órgãos de imprensa, pode-se citar o mais longevo deles, a Gazeta Polonesa no Brasil, que circulou ininterruptamente entre 1892 e 1941. Enfim, duas federações de escolas, uma laica (Kultura) e outra católica (Oswiata) congregaram 109 escolas de ensino fundamental e médio, espalhadas por toda a Região Sul, até seu desaparecimento, na esteira dos decretos nacionalizadores dos anos 1930.

As formas de organização parecem ter sido tão intensas que, como seus congêneres italianos ou alemães, alguns poloneses nacionalistas não emigrados, a partir do final do século XIX, interessaram-se pelo potencial colonizador, no sentido imperial do termo, que residia sobre os imigrantes (Gabaccia et alii, 2006: 86-87). A ideia de fundar uma colônia - Nowa Polska - no território brasileiro, assim como outras potências europeias haviam feito na África, por absurda que pareça aos olhos de hoje, foi realmente considerada e é de se pensar que isso foi possível devido ao grande número de poloneses instalados no Paraná e mesmo das formas de organização social - escolas, associações esportivas, órgãos de imprensa - existentes. Ao integrar os imigrantes entre si, e não necessariamente à sociedade nacional, todas essas formas de organização social podem ter criado, em sentido difícil de especificar,
14. A sociedade abrigou uma escola fundamental, um coral e uma banda de música. Sua atuação foi importante na organização do Primeiro Congresso Polonês, cujo objetivo era reunir imigrantes poloneses que residiam na América do Sul para planejar ações políticas que levassem a reconquista da independência da Polônia. 
novos processos de identificação, a meio caminho entre a nova e a antiga realidade. Durante os anos 1920 e 1930, até as vésperas da famosa "campanha de nacionalização", o governo brasileiro (e mesmo o executivo local) continuavam considerando os imigrantes em geral como parte de um grande projeto nacional de colonização e povoamento. Mas nem os imigrantes, nem os políticos da jovem nação polonesa que acabara de reconquistar sua independência (1920), nem tampouco os representantes do governo brasileiro parecem ter se dado conta de uma realidade social que em muito ultrapassava o sentido estritamente nacional ao qual a imigração havia sido associada. Mas diante de um quadro de vida social aparentemente tão intenso, como entender o surgimento do preconceito contra os descendentes de imigrantes poloneses em Curitiba?

\section{O preconceito contra os poloneses}

15. No prefácio de Cor e mobilidade social em Florianópolis, Florestan afirmava: "Estamos tão convencidos de que 'o Brasil constitui uma democracia racial', que aplicamos mal mesmo as regras do bom senso na avaliação dos resultados a que chegam os investigadores" (Fernandes, 1960: $\mathrm{XI}$ ).

16. O termo "Polonês" referia-se aos imigrantes, aos filhos e aos netos de poloneses. Em seus artigos, lanni também utilizaria esse termo para referir-se aos descendentes de imigrantes de primeira, segunda ou terceira gerações, ou seja, ao polonês no exterior, a seus filhos e a seus netos.
Logo após os resultados da pesquisa da Unesco, Florestan pretendeu demonstrar o quão distante da realidade estava o modelo, largamente aceito, das relações raciais tolerantes (ou democráticas) proposto por Freyre ${ }^{15}$. Florestan já havia demostrado isso em relação à cidade de São Paulo, na pesquisa realizada com Roger Bastide, apesar das pequenas diferenças de opinião existentes entre os dois (Pereira, 1996). Florestan e sua equipe estavam convencidos de que encontrariam preconceito racial, também na Região Sul. A questão era entender o modus operandi desse preconceito na nova região. Na perspectiva de Florestan, a sociedade brasileira, àquela época, caminhava em direção à modernização e à industrialização de suas estruturas produtivas, pelo menos em suas Regiões Sul e Sudeste. A estrutura racial e o passado escravocrata estariam (deveriam estar?) trazendo problemas a esse processo. Eis porque a questão racial era tão crucial e porque o resultado dessa nova pesquisa, para Florestan e seu grupo, seria tão decisivo para o futuro do país.

A leitura dos livros e artigos de lanni revela que a presença de grandes grupos de imigrantes nas cidades selecionadas para a pesquisa (Curitiba, Florianópolis, Porto Alegre e Pelotas) não havia sido devidamente aquilatada. O autor logo perceberia que o modelo "brancos e negros em processo de miscigenação" não cobria todas as situações de conflito entre os grupos, deixando de lado, em particular, os conflitos entre os próprios grupos de imigrantes, mesmo quando seus membros pertenciam à mesma classe social. Ao analisar os diversos grupos de imigrantes em Curitiba, lanni rapidamente percebeu que os poloneses e seus descendentes sofriam muito mais preconceito e atitudes discriminatórios do que qualquer outro grupo étnico. Durante suas entrevistas, ele ouviu diversas vezes, de homens e mulheres indistintamente, que eles nunca se casariam com um "polonês"16 ou que eles dificilmente aceitariam que alguém de sua família se casasse com um imigrante ou descendente de polonês. 
Ianni decidiu verificar o preconceito encontrado incluindo perguntas específicas sobre a aceitação ou a rejeição do casamento com membros de outros grupos, para si e para irmãos, em seus questionários, conforme vemos no Quadro 1.

\section{QUADRO 1}

ÍNDICE DE ACEITAÇÃO E REJEIÇÃO PARA O CASAMENTO (\%)

\begin{tabular}{|l|c|c|c|c|c|c|c|c|}
\cline { 2 - 11 } \multicolumn{1}{c|}{} & \multicolumn{2}{|c|}{ Alemão } & \multicolumn{2}{|c|}{ Italiano } & \multicolumn{3}{c|}{ Polonês } & \multicolumn{3}{c|}{ Judeu } \\
\cline { 2 - 11 } \multicolumn{1}{l|}{} & $\operatorname{sim}$ & não & $\operatorname{sim}$ & não & sim & não & sim & não \\
\hline Você aprovaria o casamento de seu irmão com & 70 & 30 & 84 & 16 & 45 & 55 & 41 & 59 \\
\hline Você aprovaria o casamento se sua irmã com & 68 & 32 & 82 & 18 & 48 & 52 & 35 & 65 \\
\hline Você gostaria de casar-se com & 59 & 41 & 76 & 24 & 33 & 67 & 30 & 70 \\
\hline Fonte: lanni (1960: 327).
\end{tabular}

Deve-se salientar que embora o número de questionários enviados tenha sido grande (2.335), apenas aproximadamente 10\% foram respondidos (223). Dentre esses, como se pode ver no Quadro 1, algumas diferenças, consideradas importantes, surgiram. Casar-se com um "descendente de italiano" foi aceito por $84 \%$ dos entrevistados. Os descendentes de alemães vinham em segundo lugar na preferência local, enquanto que apenas $41 \%$ eram favoráveis ao casamento com descendentes de judeus ou que $45 \%$ eram favoráveis ao casamento com descendentes de poloneses. Os dados parecem indicar, inicialmente, uma grande capacidade da comunidade local em diferenciar quem era quem, revelando assim que, aos seus olhos, um descendente de polonês deveria ter características relativamente diferentes de descendentes de judeus ou de alemães. Isso sobretudo porque, conforme afirma Ianni, eram os alemães e os poloneses aqueles mais reticentes em contrair matrimônio com os italianos (Ianni, 1960: 327) ${ }^{17}$. Em segundo lugar, chama a atenção a pequena variação das respostas sobre a aceitação do casamento de um irmão ou irmã, revelando talvez que as representações eram efetivamente sobre o grupo, o que não seria tão esperado tendo em vista os dotes, as heranças etc. Há ainda o fato de o grupo dos judeus aparecer na última posição em relação à escolha do cônjuge, ainda que apenas levemente inferior ao grupo polonês. Ianni, embora reconhecendo esse alto índice de rejeição, não pareceu surpreender-se com o fato, tendo afirmado assim que

[...] as opiniões acerca do judeu em Curitiba são aquelas comuns em São Paulo, por exemplo, o que nos sugere a hipótese de que aquelas opiniões são "brasileiras" e não elaboradas na própria comunidade; isto é, que elas atingiram Curitiba por difusão da mesma forma que alguns estereótipos sobre o negro (lanni, 1960: 328) ${ }^{18}$.

Ao isolar o caso dos judeus, lanni (1960) tratou especificamente dos poloneses. Como ele próprio declarou, o preconceito contra esse grupo surgiu de forma inesperada:
17. Aparentemente preocupado em explicar esse fato, lanni (1960: 324) afirmou, citando do estudo de Mortara (1950), que alemães, russos e poloneses estavam entre aqueles imigrantes que mais falavam o idioma original. E que o mesmo acontecia com seus filhos.

18. Nas páginas 328 e 329, lanni (1960) apresenta exemplos que confirmam sua hipótese sobre a difusão nacional dos estereótipos contra judeus. 
Ao iniciar a investigação acerca da situação social do negro em Curitiba, um informante nos prestou um esclarecimento que, de início, pareceu-nos gracejo de mau gosto, tão inesperado foi. "Aqui, afirmou, não há negros. "O negro do Paraná é o polaco". Ficamos pasmados com a declaração e, mais ainda, porque ele a fazia seriamente (lanni, 1960: 325).

Estudos da literatura e da história local, além das entrevistas realizadas, levaram o autor concluir inicialmente que

[...] a contínua associação do negro ao polonês parece-nos altamente relevante para o conhecimento de componentes essenciais das tensões raciais (Ianni, 1960: 329).

Se a escolha do cônjuge era realmente reveladora de preconceitos, os poloneses e seus descendentes estavam efetivamente sendo discriminados e a prova disso era sua alta taxa de rejeição. O número de entrevistas colhidas, 223, pedia precaução e modéstia nas conclusões. Por outro lado, a descoberta era instigante. Assim, "com o intuito de reunir outras evidências em relação a esse problema", lanni (1960: 330) decide incluir em seu questionário questões sobre o intercasamento. Os resultados foram sumarizados no Quadro 2.

QUADRO 2

ÍNDICE DE INTERCASAMENTO (\%)

\begin{tabular}{|l|c|c|c|c|}
\cline { 2 - 5 } \multicolumn{1}{c|}{} & Alemão & Italiano & Polonês & Total \\
\hline Casa-se com mulato & 32 & 33 & 35 & 100 \\
\hline Casa-se com negro & 32 & 26 & 42 & 100 \\
\hline Fonte: lanni (1960:330). & & & & \\
\hline
\end{tabular}

Os dados não eram tão contrastantes e o número de respostas totais pequeno: apenas 654 respostas, 424 relativas ao mulato e 230 relativos ao negro. Além disso,

19. Essa expressão, como título de seção, surge na versão desse artigo publicada em forma de capítulo sem alteração de titulo, em 1966, no livro Raças e classes sociais. Contudo, na segunda edição, publicada em 1972, título desse capítulo é ligeiramente modificado, passa a ser "A situação social do polonês". Ver: nota 25 e referências. lanni pouco comentou a semelhança dos resultados em relação a mulatos e negros. Embora os dados não fossem tão fiáveis e - isso é importante - tenham sido levantados à margem de uma pesquisa que pretendia provar a existência de preconceito racial na Região Sul, Ianni concluiu que a diversidade social em Curitiba - uma "sociedade etnicamente heterogênea" - havia criado muitos estereótipos ideológicos no seio de todas as comunidades e esses, de alguma forma, afetavam a todas elas. "Cada grupo sofre, cada um a seu turno, alguma forma de discriminação da parte dos outros, em bloco ou individualmente" (Ianni, 1960: 331).

Para exprimir essa situação, lanni cunhou a expressão "discriminação múltipla"19, insistindo, logo abaixo no texto, na existência de uma "aguda consciência da heterogeneidade racial da comunidade por parte de seus membros". 
Em princípio, eram os imigrantes e descendentes de imigrantes poloneses quem mais aceitavam casar-se com negros. Ianni concluiu assim que o polonês se encontrava realmente em posição "menos valorizada socialmente". A rejeição ao casamento com poloneses, acima comentada, talvez estivesse na origem da inclinação desses em contrair casamento com cônjuges negros. Mas isso não foi analisado e a situação social (inferior) do polonês acabou tornando-se o fato mais relevante. A prova da situação inferior dos poloneses lastreava-se ainda nos depoimentos orais obtidos, além da literatura consultada (livros científicos, literatura, jornais etc.). Contudo, essa última merece reparos. A título de exemplo, lanni valeu-se de O Brasil diferente, de Wilson Martins ${ }^{20}$, e do livro Vale do Itajaí. Jornadas de civismo, escrito no final dos anos $1930^{21}$ pelo jovem oficial do exército, Hugo Bethlem, que, prenunciando a "campanha de nacionalização", acusava as comunidades de imigrantes em geral, e não apenas de imigrantes poloneses, de desnacionalizar o Brasil. Com tais evidências, lanni findou por tomar a si a expressão "polacos", largamente utilizada para denominar os imigrantes poloneses, como nova evidência do preconceito.

Em 1960, no hoje clássico Do polonês ao polaco, lanni sintetizou suas conclusões nesses termos: "no quadro da ideologia racial dominante na comunidade, não é nem polonês nem brasileiro: é polaco" (Ianni, 1960: 336). Essa nova categoria social, é claro, era de alguma forma um produto em transição, mas era, sobretudo, socialmente desvalorizada. Sem colocar nesses termos, Ianni apontava, talvez mesmo com certo ineditismo, para a existência de um preconceito contra brancos, contra um grupo de imigrantes europeus brancos que, à diferença da tradicional acusação feita aos descendentes de alemães no Brasil, sem nunca ter oficialmente atentado contra a soberania nacional ${ }^{22}$, era marginalizado.

As entrevistas feitas por lanni estão desaparecidas ${ }^{23}$. Tudo o que sobre elas sabemos são as poucas questões reproduzidas pelo próprio autor em seus trabalhos. Assim, é bastante difícil avançar hipóteses seguras, contestando ou corroborando suas conclusões. Mas, segundo as evidências apresentadas, os imigrantes poloneses e seus descendentes sofriam preconceitos, haviam substituído os afrodescendentes na escala social local. O preconceito racial direcionado aos últimos fora transferido. Essa conclusão alinhava-se com a expectativa da pesquisa encabeçada por Florestan. Mesmo no Sul do Brasil havia racismo e isso contribuía, uma vez mais, para destronar a hipótese de Freyre e para aprofundar as descobertas da pesquisa da Unesco.

O trabalho de campo de lanni banhou nesse caldo e, desse ponto de vista, a pesquisa e seus resultados (esperados) estavam perfeitos. Com efeito, no prefácio de Cor e mobilidade social em Florianópolis, Florestan (1960: XIV-XV) afirmou aquilo que de nossa "herança cultural" era incompatível com a "implantação da democracia no Brasil". O racismo, de certa forma, já estava provado, mas precisava ser
20. Nesse livro, é notória a preferência do autor para com o grupo alemão e sua animosidade demonstrada em relação ao grupo polonês. Para maiores detalhes, ver Oliveira (2007).

21. Em viagem pelos estados do Sul, Bethlem denunciava o alto grau de desnacionalização encontrado nas comunidades de imigrantes. Ver referências.

22. Contudo, como mostramos alhures (Oliveira, 2009), houve um desejo, logo abandonado, de criar uma colônia, no sentido imperial do termo, no Brasil.

23. Por sugestão de Renato Ortiz, escrevemos a esse respeito ao professor Seggato, casado com uma das filhas de lanni. Em sua resposta, ele nos disse que as entrevistas estão perdidas, provavelmente jogadas fora. 
24. Em sentido inverso, os poloneses consideravam os alemães como invasores de seus territórios.

25. Chamamos a atenção do leitor para certa confusão decorrente da semelhança de títulos de trabalhos diferentes. Esse projeto foi publicado anos mais tarde, em 1966, sob o título de "A situação social do polonês. Projeto de estudo" no livro Raças e classes sociais no Brasil. Não foi incluído na segunda edição desse mesmo livro, mas foi republicado em 1978, em obra organizada por Sedi Hirano. Existe ainda outro texto de título semelhante, "A situação social do Polonês", que tem por origem o artigo "Do polonês ao polaco", acima analisado. Ver nota 19 e referências.

26. Para maiores detalhes, ver a sociologia da imigração clássica em Oliveira (2014a).

27. Utilizamos aqui a primeira versão, publicada na revista Sociologia e cujo título era "A situação social do polonês em Curitiba". superado! A existência de preconceito contra o polonês apenas reforçava a tese de que o racismo era parte estrutural da sociedade brasileira. Mas mesmo isso sendo fato, permanecia relativamente obscura a existência da "discriminação múltipla", ou seja, da discriminação aparentemente cega que atingia a todos indistintamente. 0 caráter etnicamente heterogêneo da sociedade local, por si só, evidencia essas formas múltiplas de discriminação. Mas qual seria sua origem? E por que afetava mais diretamente os descendentes de poloneses?

No início de seus estudos, lanni contou com referências literárias, jornais e livros sobre a história do Paraná. Nesses, os imigrantes poloneses eram descritos como camponeses iletrados, extremamente católicos e arredios. Suas filhas empregavam-se como domésticas nas residências da elite curitibana. Isso tudo the pareceu suficiente em um primeiro momento. Como demonstramos alhures (Oliveira, 2009), os imigrantes poloneses sofreram preconceitos por parte da elite local, mas também dos imigrantes alemães, que os consideravam um povo "sem pátria" ou "sem nação", aqueles que "teriam vendido sua pátria por um prato de comida", como se dizia então ${ }^{24}$. Ianni teve contato com esses fatos e decidiu ir mais longe. Para investigar mais a fundo a questão, elaborou um projeto de pesquisa e o intitulou "A situação social do polonês em Curitiba", publicando-o pela primeira vez em dezembro de 1961, na revista Sociologia ${ }^{25}$. Esse projeto merece uma análise mais detalhada.

\section{O projeto de pesquisa sobre os imigrantes poloneses}

O projeto de estudo que lanni redigiria e publicaria duas vezes, em 1961 e em 1966, atesta o interesse do autor em aprofundar sua descoberta. Além de um quadro teórico bastante refinado, onde se observa o emprego de conceitos sociológicos clássicos, como assimilação e integração, além da definição e categorização dos descendentes de imigrantes por gerações, é clara a pretensão de investigar as origens daquela realidade social realmente distinta. No projeto, a questão principal não era mais explicar tão somente o preconceito, mas compreender, num plano mais geral, a "situação social do polonês", do ponto de vista educacional, cultural, social e profissional. O tamanho da família e mesmo a nutrição seriam levados em conta! Além desses fatores, a compreensão social do polonês necessitaria o estudo das demais comunidades de imigrantes e suas inter-relações. Implicaria enfim - como haviam feito Thomas e Znaniecki, no clássico da sociologia da imigração - estudar o "polonês antes de emigrar"26. Ianni elaborou um cronograma, "com programação e execução do projeto". Até hoje, a leitura desse material vale como exemplo, entre outras coisas, de rigor metodológico e de abrangência interdisciplinar. Infelizmente, para a sociologia brasileira, lanni não levou a cabo a pesquisa projetada e as razões disso permanecem incertas.

O projeto ${ }^{27}$ foi dividido em quatro capítulos: 
1. "O polonês antes de emigrar (ou na comunidade originária)";

2. "O imigrante em Curitiba";

3. "A integração social do polonês";

4. "Considerações finais".

O "objetivo central da pesquisa" - a integração social do polonês - seria alcançado respondendo à seguinte pergunta: "Como explicar a presente situação social do polonês em Curitiba?" (Ianni, 1961: 382). Dois caminhos foram apontados, a saber:

1. Nos setores em que o polonês não se encontrava "perfeitamente ajustado", mais facilmente ele se integrará;

2. Nos setores onde ele se encontra "ajustado", ele não se integrará, acredita citando Eisenstadt (1954).

A hipótese focava assim no processo dinâmico dos membros da comunidade em relação à sociedade de destino, mas, até esse momento do texto, nenhuma palavra sobre possíveis preconceitos.

A execução do projeto pretendia lidar com "histórias de vida" (com ajuda de cartas, diários, autobiografias) e "histórias de caso" (trajetórias, mobilidade, ascensão etc.). A vida do polonês nos diversos setores da sociedade (instituições, grupos, empresas, clubes recreativos etc.) seria analisada em relação à estrutura socioeconômica de uma sociedade em transformação. O objetivo não era estudar a "aculturação dos poloneses", afirma, distanciando-se de tema de estudos em voga, mas, ainda com Eisenstadt, o "grau de integração social imigrante será avaliado pelo ajustamento do seu comportamento social às formas institucionalizadas de comportamento" [...] (Ianni,1961: 381).

Por fim, Ianni (1961: 384) afirma, apresentando a possível origem dos preconceitos, que na análise desse processo de integração social surgiriam determinadas "marcas raciais ou avaliações positivas ou negativas [...] manipuladas sociologicamente". Conclui, em forma de questionamento, na última página:

[...] a discriminação vigente em Curitiba contra o polonês teria sido incorporada, pela comunidade, a partir de elementos da ideologia racial dos alemães que a trouxeram da Europa, ou desenvolveu-se, desde o início, por meio da influência do meio social interno? (Ianni, 1961: 388).

Infelizmente lanni nunca executou esse projeto ${ }^{28}$.

28. Além de não ter levado adiante o seu projeto, até o momento de sua morte, em 2002, lanni nunca mais retornou a Curitiba. As razões disso não são conhecidas. 
29. Ianni reconheceu esse fato alguns anos mais tarde (lanni, 2004).

\section{Considerações finais}

Ao trabalhar a partir de hipóteses definidas por Florestan, com base nos resultados da pesquisa da Unesco, de suas publicações individuais e com Roger Bastide, a interpretação de lanni sobre os resultados de sua pesquisa não poderiam ter sido diferentes. O paralelo estabelecido entre o preconceito dirigido aos descendentes de imigrantes poloneses e o racismo enfrentado por afrodescendentes foi alcançado sem grande dificuldade, além de ter sido sugerido por testemunhos orais colhidos ${ }^{29}$.

As hipóteses avançadas nos artigos apontam, contudo, para aspectos muito mais gerais, para além das conclusões esperadas. Ianni apresentou e qualificou comportamentos preconceituosos pouco conhecidos. Infelizmente, ele mesmo não explorou suas descobertas, como pretendia, tendo retornado esporadicamente ao tema da imigração, como demonstraremos em trabalho futuro. É possível dizer, contudo, que lanni descobriu tipos de preconceitos mais ligados à história da imigração no Sul do Brasil do que necessariamente ao passado escravocrata. As inesperadas descobertas que deixaram o autor "pasmo" podem estar ligadas hoje a toda uma série de estudos que revelam atos discriminatórios contra diversos grupos de imigrantes no Brasil. A título de exemplo, o preconceito sofrido por poloneses trouxe à tona conflitos entre os últimos e os imigrantes alemães, em especial durante as duas guerras mundiais. Imigrantes poloneses também mantiveram tensas relações com outras comunidades de imigrantes, como os ucranianos no Paraná. Por outro lado, houve também outras atitudes inesperadas, como a tentativa de estabelecer uma colônia polonesa no Brasil.

Podemos dizer que as diversas formas de preconceito que grupos de imigrantes sofreram ultrapassam claramente o quadro racial tradicional e, de certa forma, são menos visíveis do que as atitudes racistas conhecidas. Esse foi talvez o principal legado desses estudos de lanni. Embora bem recebidos e bem considerados pelas autoridades migratórias brasileiras desde o início da imigração, europeus brancos sofreram, aqui e ali, tipos variados de preconceitos. Temos aí campo de estudos ainda bastante aberto, além de ser importante capítulo da trajetória da sociologia da imigração no Brasil, ainda inexplorado.

Abstract: After the Unesco research about racial relations in Brazil, Florestan Fernandes headed a new team of young Brazilian sociologists, composed by Fernando Henrique Cardoso, Roberto Jardim Moreira and Octávio Ianni, to deal with the same theme in Southern Brazil. The region was omitted from the first Unesco research. The states of Paraná and Santa Catarina were put in charge of Octávio lanni, the last one shared with Fernando Henrique Cardoso. Even the main goal of the research was to prove prejudice among Black and White in Southern Brazil lanni was astonished to find out that there was also prejudice against immigrant poles and their descen- 
dants in the city of Curitiba, capital of the state of Paraná. Ianni began to investigate the theme and published later few articles about that where He tried to explain the unexpected prejudice. To investigate further the phenomenon, He prepared a project plan and published it. Unhappily, this new research was never accomplished.

Keywords: racial relations, Unesco, prejudice, immigrant poles, city of Curitiba.

\section{Referências}

AZEVEDO, Thales de. Les élites de couleur dans une ville brésilienne. Paris: Unesco, 1953.

BASTIDE, Roger. Estudos afro-brasileiros. São Paulo: Perspectiva, 1973.

BASTIDE, Roger; FERNANDES, Florestan. Relações raciais entre negros e brancos em São Paulo. Ensaio sociológico sobre as origens, as manifestações e os efeitos do preconceito de cor no município de São Paulo. São Paulo: Editora Anhembi, 1955.

BASTOS, Elide R. Octavio Ianni: a questão racial e a questão nacional. In: FALEIROS, Maria I. L.; CRESPO, Regina A. Humanismo e compromisso: ensaios sobre Octavio lanni. São Paulo: Editora Unesp, 1996.

BETHLEM, Hugo. Vale do Itajaí. Jornadas de civismo. Rio de Janeiro: Livraria José Olympio Editora, 1939.

CAMPOS, Maria J. Arthur Ramos: luz e sombra na antropologia brasileira uma versão da democracia racial no Brasil nos anos 1930 e 1940. (Dissertação de Mestrado) - Universidade de São Paulo, São Paulo, 2003.

CARDOSO, Fernando H. Capitalismo e escravidão no Brasil meridional. O negro na sociedade escravocrata do Rio Grande do Sul. 5. ed. Rio de Janeiro: Civilização Brasileira, 2003.

CARDOSO, Fernando H; MOREIRA, Renato J.; IANNI, Octávio. Estudo das relações entre negros e brancos no Brasil Meridional. Anais da I/ Reunião Brasileira de Antropologia. Salvador, 1957.

CARDOSO, Fernando Henrique; IANNI, Octávio. Cor e mobilidade social em Florianópolis. São Paulo: Companhia Editora Nacional, 1960.

EINSENSTADT, Shmuel N. The absorption of Immigrants. London: Routledge, 1954.

FERNANDES, Florestan. Prefácio. In: CARDOSO, Fernando Henrique; IANNI, Octavio. Côr e mobilidade social em Florianópolis, p. XI-XL. São Paulo: Companhia Editora Nacional, 1960. 
FREYRE, Gilberto; RAMOS, Arthur. Novos estudos afro-brasileiros: trabalhos apresentados ao I Congresso Afro-Brasileiro do Recife. Rio de Janeiro: Civilização Brasileira, 1937.

GABACCIA, Donna R. et alii. Émigration et construction nationale en Europe. In: GREEN, Nancy; WEIL, François. Citoyenneté et émigration. Les politiques du départ. Paris : Editions Ehess, 2006.

GARCIA Jr., Afrânio. A dependência da política: Fernando Henrique Cardoso e a sociologia no Brasil. Tempo Social, v. 16, n. 1, p. 285-300, 2004.

GUIMARÃES, Alfredo S. O projeto Unesco na Bahia. Comunicação ao Colóquio Internacional "O projeto Unesco no Brasil: uma volta crítica ao campo 50 anos depois". Salvador, Centro de Estudos Afro-Orientais da Universidade Federal da Bahia, 2004. Disponível em: <http://www.ceao.ufba.br/unesco/01Paper-ASG1.htm>. Acesso em: 23 Jul. 2013.

HEMPEL, Antônio. Os poloneses no Brasil. In: Anais da Comunidade Brasileiro Polonesa, v. VII, p. 11-99. Curitiba: Superintendência do Centenário da Imigração polonesa ao Paraná, 1973.

KLOBUKOWSKI, Stanislaw. Anais da Comunidade Brasileiro Polonesa, v. IV, p. 15-107. Curitiba: Superintendência do Centenário da Imigração polonesa ao Paraná, 1971.

KULA, Marcin. Carta dos imigrantes do Brasil. Anais da Comunidade Brasileiro Polonesa, v. VIII, p. 9-117. Curitiba: Superintendência do Centenário da Imigração polonesa ao Paraná, 1977.

IANNI, Octavio. Entrevista de Octávio Ianni. Estudos Avançados, v. 18, n. 50, p. 6-20, 2004.

. A situação social do polonês: projeto de estudo. In: HIRANO, Sedi (Org.). Pesquisa social. Projeto e planejamento, p. 193-214. 2. ed. São Paulo: T. A. Queiroz Editor, 1988 [1978].

- A situação social do polonês. In: IANNI, Octavio. Raças e classes sociais no Brasil, p. 169-198. 2. ed. São Paulo: Civilização Brasileira, 1972.

. A situação social do polonês (Projeto de estudo). In: IANNI, Octavio. Raças e classes sociais no Brasil, p. 147-167. São Paulo: Civilização Brasileira, 1966.

- Do polonês ao polaco. In: IANNI, Octavio. Raças e classes sociais no Brasil, p. 117-146. São Paulo: Civilização Brasileira, 1966. 
— . A situação social do polonês em Curitiba. Sociologia, v. XXXIII, n. 4, p. 375388, 1961.

. Do polonês ao polaco. Revista do Museu Paulista. Nova Série, v. XII, p. 315$338,1960$.

. O estudo da situação racial brasileira. Revista Brasiliense, n. 19, p. 79-86, 1958.

JACKSON, Luiz C. Gerações pioneiras na sociologia paulista (1934-1969). Tempo Social, v.19, n. 1, p.115-130, 2007.

Tensões e disputas na sociologia paulista (1940-1970). Revista Brasileira de Ciências Sociais, v. 65, p. 33-49, 2007a.

- A sociologia paulista nas revistas especializadas (1940-65). Tempo Social, v. 16, n. 1, p. 263-288, 2004.

MAIO, Marcos C. O projeto da Unesco e a agenda das ciências sociais no Brasil dos anos 40 e 50. Revista Brasileira de Ciências Sociais, v. 14, n. 41, p. 141-158, 1999.

- Tempo controverso. Gilberto Freyre e o projeto Unesco. Tempo Social, v. 11, n. 1, p. 111-136, 1999.

. A questão racial no pensamento de Guerreiro Ramos. In: MAIO, Marcos C.; SANTOS, Ricardo V. (Orgs.). Raça, ciência e sociedade. Rio de Janeiro: Editora Fiocruz/Centro Cultural Banco do Brasil, 1996.

MAIO, Marcos C. et alii. Donald Pierson e o projeto do Vale do São Francisco. Dados. Revista de Ciências Sociais, v. 56, n. 2, p. 245-284, 2013.

- O projeto da Unesco e a agenda das ciências sociais no Brasil dos anos 40 e 50. Revista Brasileira de Ciências Sociais, v. 14, n.1, p. 141-158, 1999.

MAUREL, Chloé. La question des races. Gradhiva, n. 5, 2007 . Disponível em: <http:// gradhiva.revues.org/815>. Consultado em: 11 Abr. 2011.

—. La question des races. Gradhiva, n. 5, 2007. Disponível em: <http://gradhiva. revues.org.815>. Acesso em: 11 Abr. 2011.

MÉTRAUX, Alfred. Brazil: Land of harmony for all races? Courier. Publication of the United Nations Education, v. IV, n. 4, p. 3, Abr. 1951.

. Unesco and the racial problem. International Social Science Bulletin, v. II, n. 3, p. 384-390, 1950. 
MORTARA, Giorgio. Algumas observações sobre a assimilação linguística dos imigrados para o Brasil e de seus descendentes. Estudos sobre as línguas estrangeiras e aborígenes faladas no Brasil. Série Estatística Cultural, n. 2. Rio de Janeiro: IBGE, 1950.

OLIVEIRA, Márcio de. A chapter of in the history of Brazilian sociology: Unesco research about race relations and the unexpected prejudice against Poles in Curitiba (Paraná). In: FLECK, Christian; HESS, Andreas (Ed.). Knowledge for whom? Public sociology in the making, p. 185-201. London: Ashgate, 2014.

- O tema da imigração na sociologia clássica. Dados. Revista de Ciências Sociais, v. 57, n. 1, p. 73-100, 2014a.

_. Organizações sociais dos imigrantes poloneses e seus descendentes em Curitiba (Brasil), 1890-1938. In: HECKER, Alexandre; MARTINS, Ismênia de L. (Orgs.). E/imigrações: histórias, culturas e trajetórias, p. 83-98. São Paulo: Expressão e Arte Editora, 2010.

- De la double colonisation au préjugé: Polonais dans le sud du Brésil. Migrations Société, v. 21, n. 123-124, p. 289-304, 2009.

_. Imigração e diferença no Sul do Brasil. Novos Mundos, Mundos Nuevos, v. 7, 2007. Disponível em: < http://nuevomundo.revues.org/5287>. Consultado em: 12 Maio 2012.

221,2005

PEREIRA, João B. B. A questão racial na obra de Florestan Fernandes. Revista da USP, n. 29, p. 34-41, 1996.

PEIXOTO, Fernanda A. Diálogos brasileiros: uma análise da obra de Roger Bastide. São Paulo: EdUSP; Fapesp, 2000.

PEIXOTO, Fernanda A.; SIMÕES, Júlio A. A Revista de Antropologia e as ciências sociais em São Paulo: notas sobre algumas cenas e alguns debates. Revista de Antropologia, v. 46, n. 2, p. 383-409, 2003.

PIERSON, Donald. Cruz das Almas. Rio de Janeiro: Livraria José Olympio Editora, 1966 [1951].

. Brancos e pretos na Bahia: estudo de contato racial. São Paulo, Companhia Editora Nacional, 1945 [1942]. 
RAMOS, Arthur. Os grandes problemas da antropologia brasileira. Sociologia, v. X, n. 4, p. 213-226, 1948.

. As culturas negras no novo mundo: o negro brasileiro. São Paulo: Companhia Editora Nacional, 1946.

- Guerra e relações de raça. Rio de Janeiro: Departamento Editorial da União Nacional dos Estudantes, 1943.

. A aculturação negra no Brasil. São Paulo: Companhia Editora Nacional, 1942.

SKIDMORE, Thomas E. Black into white: race and nationality in brazilian thought. Durham: Duke University Press, 1993 [1974].

WAGLEY, Charles (Ed.). Race and class in rural Brazil. Paris: Unesco, 1952. 
